\title{
Cluster ion polymerization of serine and tryptophan, the water loss channel ${ }^{\star}$
}

\author{
Lukas Tiefenthaler $^{1}$, Jaroslav Kočišek ${ }^{2}$, and Paul Scheier ${ }^{1, \text { a }}$ \\ 1 Institut für Ionenphysik und Angewandte Physik, Universität Innsbruck, Technikerstr. 25, A-6020 Innsbruck, Austria \\ 2 J. Heyrovský Institute of Physical Chemistry of the Czech Academy of Sciences, Dolejškova 3, 18223 Prague, Czech Republic
}

Received 8 January 2020 / Received in final form 27 February 2020

Published online 1 May 2020

(C) The Author(s) 2020. This article is published with open access at Springerlink.com

\begin{abstract}
We present an experimental study on the stability of cluster cations formed by the assembly of tryptophan or serine moelcules inside charged helium droplets and subsequent droplet evaporation. The stability is probed via collision induced dissociation and mass spectrometry. We focus on the neutral loss of $18 \mathrm{Da}$ that was previously proposed to result in the formation of an amide bond in amino acid clusters. We show that the cluster cations formed by the neutral loss of $18 \mathrm{Da}$ from protonated parent cluster ion precursors are softly, presumably van der Waals, bound similar to the parent and protonated parent cluster cations. Cluster cations formed after neutral loss of $18 \mathrm{Da}$ from the parent cluster cations are strongly bound, indicating the formation of new covalent bonds. Even though we observe a signal at $m / z$ corresponding to dipeptide cations, their collision induced dissociation fragmentation does not allow unambiguous identification of their structure, particularly the amide bond. Our study at cryogenic conditions of He droplets demonstrates that peptide formation by the cluster ion polymerization is not a barrierless process and the formation of amide bonds may depend on activation methods and available catalysts.
\end{abstract}

\section{Introduction}

Cluster ions of amino acids have attracted significant interest during the last few years due to the high stability of their selected homochiral clusters, particulary the serine octamer [1-6] and its substituents $[7,8]$. Chiral selectivity of some amino acid clusters may be a key for the Earth's biomolecular homochirality [9-11]. The enantiomer selective assembly of amino acids opens new possibilities for chiral purification of amino acids or preparation of polypeptides $[12,13]$.

The formation of polypeptides via cluster ion polymerization is of particular importance. A breakthrough in this direction was made by the observation that, after activation, amino acid cluster ions effectively lose a neutral water molecule [14,15], which indicates the formation of the amide bond. UV activation of amino acid complexes [16], ion/ion reactions [17] or coordination of amino acids with $\mathrm{Cu}^{2+}$ on aerosol surfaces [18] were used to gain high cross sections for the formation of small peptides. The importance of this reaction lies in the possibility of artificially producing isolated homochiral peptides. Even though peptide building in nature is a complex biological process [19], fundamental insights into peptide stability

\footnotetext{
* Contribution to the Topical Issue "Atomic Cluster Collisions (2019)", edited by Alexey Verkhovtsev, Pablo de Vera, Nigel J. Mason, Andrey V. Solov'yov.

a e-mail: Paul.Scheier@uibk.ac.at
}

concerning chirality or charge state gives important information about the molecular characteristics and energy barriers that may drive the process.

Previous studies of amino acid fragmentation indicate that the formation of an amide bond will depend on how the precursor clusters are formed. After chemical ionization of amino acid dimers, prepared by the assembly of sublimed monomers, Leclerq and Desiderio [20] suggested that the fragmentation channel corresponding to neutral loss of $18 \mathrm{Da}$ from protonated cluster ions actually corresponds to ions with an amino group modified by the interaction with the side chain group of the second constituent of the dimer and loss of the carboxyl group. This fragmentation mechanism was then confirmed by another study [21]. On the other hand, high resolution mass spectrometry of cations formed after collision induced dissociation (CID) of amino acid clusters prepared by electrospray demonstrated that water loss can be efficient, in agreement with the proposed mechanism of amide bond formation [22]. Surprisingly, in the work of Singh [22], formation of dipeptides was not observed for serine, the most studied molecule in this context. This may be caused by the low intensity of the water loss channel from serine and preferential charge localization on the water fragment [23]. Another important fact is that in serine, water is preferentially released from the side chain and complex rearrangement will be needed for amide bond formation [24]. 


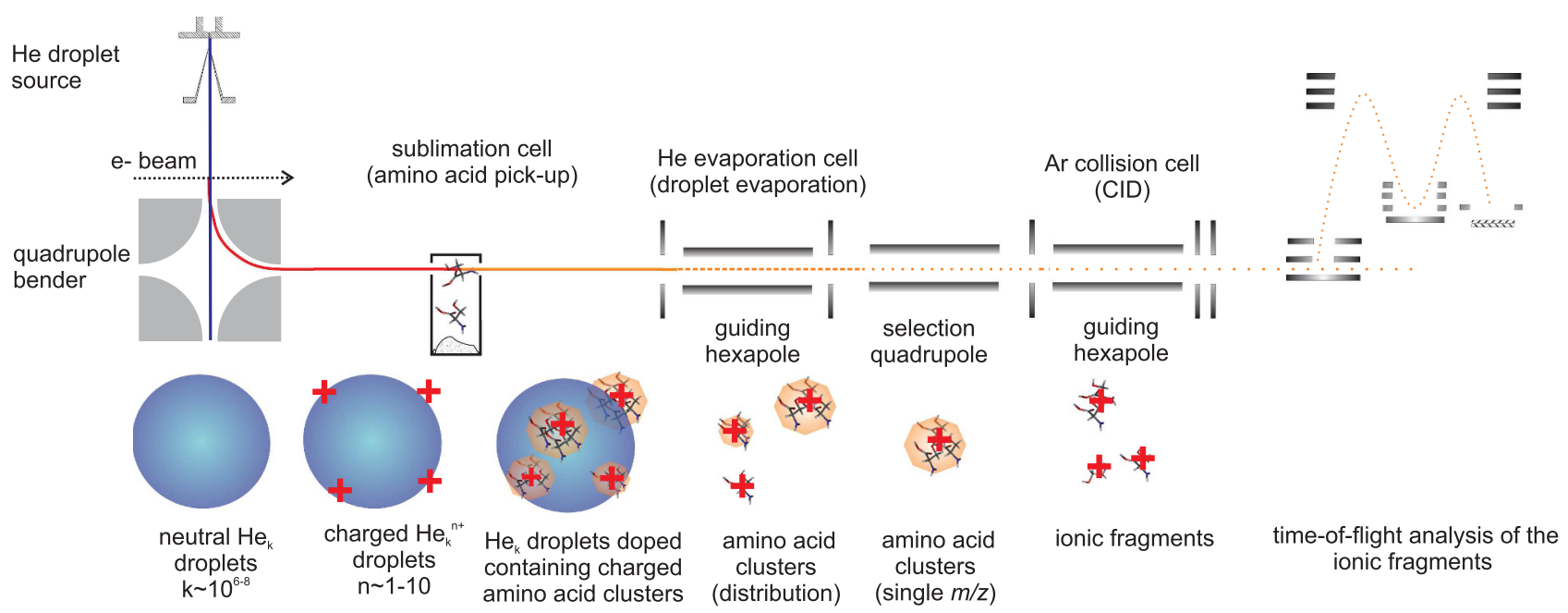

Fig. 1. Sketch of the experimental apparatus and approach.

It is, therefore, not completely clear how the cluster structure and internal energy, activation methods or catalysts (e.g. $[18,25])$ influence the cluster ion polymerization of amino acids to form small peptides. Here we used a novel He cluster ion assembly technique to prepare amino acid cluster ions of yet another character. Using the CID approach, we probe the stability of these precursor ions (p.i.) as well as cations corresponding to neutral loss of $18 \mathrm{Da}$ from nonprotonated or protonated parent cations.

We selected two molecules for the study, L-serine (Ser) containing an $\mathrm{OH}$ group on the side chain and L-tryptophan (Trp) that does not contain an $\mathrm{OH}$ group on the side chain. Another important difference of the studied amino acids is in their polarity. While Ser is polar, Trp is nonpolar which may further influence the noncovalent bonding character.

\section{Methods}

The experiments were performed on a modified tandem mass spectrometer Waters Q-TOF Ultima combined with a novel cluster source developed in our laboratory and recently described in [26]. A sketch of the setup is shown in Figure 1.

The cluster ion assembly process was started by the formation of a He droplet beam by expanding $\mathrm{He}$ gas at a stagnation pressure of 20 bar through a $5.7 \mu \mathrm{m}$ diameter nozzle cooled down to $8.9 \mathrm{~K}$, into a first vacuum chamber of the setup (at $\sim 10^{-4}$ mbar under operation conditions). The droplets were multiply charged by electron ionization and a part of their $m / z$ distribution was deflected by a quadrupole bender towards the pickup cell containing vapors of the studied amino acid. Cluster ions of amino acids were assembled inside the He droplets after pickup of their respective molecular precursors L-Serine (Sigma Aldrich 99.5\%) or L-Tryptophan (Sigma Aldrich 99.5\%).

After pickup, charge transfer from $\mathrm{He}_{2}^{+}$to the first arriving dopant is highly exothermic. For the studied system with ionization energies for $\mathrm{He}(\mathrm{IE}=24.59 \mathrm{eV})$ and

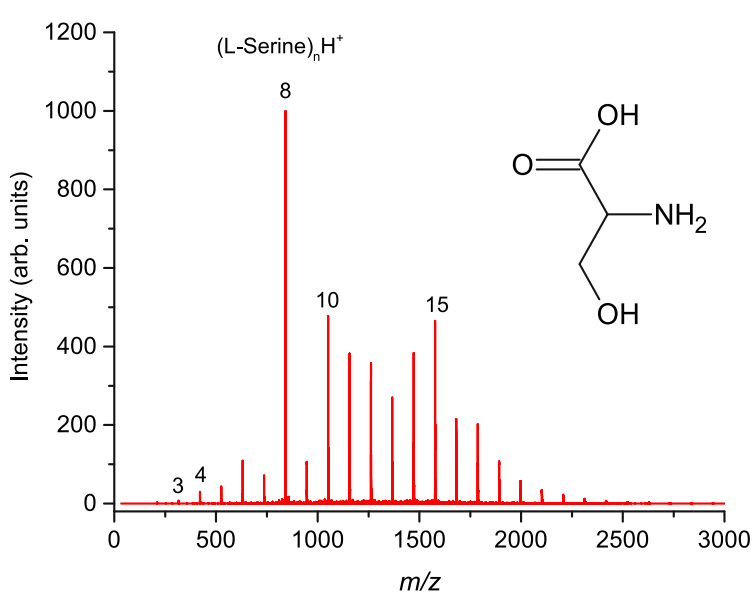

Fig. 2. Mass spectrum of positively charged ions formed upon pickup of L-serine into charged He droplets. The dominant ions can be assigned to protonated serine clusters $\left(\mathrm{C}_{3} \mathrm{H}_{7} \mathrm{NO}_{3}\right)_{n} \mathrm{H}^{+}$. The numbers above selected peaks designate the cluster size $n$ of the corresponding ion.

$\mathrm{He}_{2}(\mathrm{IE}=22.22 \mathrm{eV})$ [27], Ser $(\mathrm{IE} \sim 10 \mathrm{eV}$ [28] $)$ and Trp $(7.4 \mathrm{eV})[29]$, even excited charged states can be populated, which enable dissociation. However, as known from experiments ionizing neutral clusters inside He droplets [30], these states can be quenched in the cold He environment and for the most part molecular cluster ions are formed. In the case of amino acids the parent cations are, however, metastable with respect to loss of a dehydrogenated amino acid radical and therefore the spectrum is dominated by protonated species [31].

The amino acid cluster ions were released from the $\mathrm{He}$ matrix by evaporation of the helium in the evaporation cell of the instrument - a RF-hexapole filled with room temperature He gas. In simple MS mode, the cluster ions were transported to the reflectron time of flight mass spectrometer and analyzed. This way the initial mass spectra were obtained as depicted in Figures 2 and 3. Depending on the pressure in the evaporation cell and the collision 


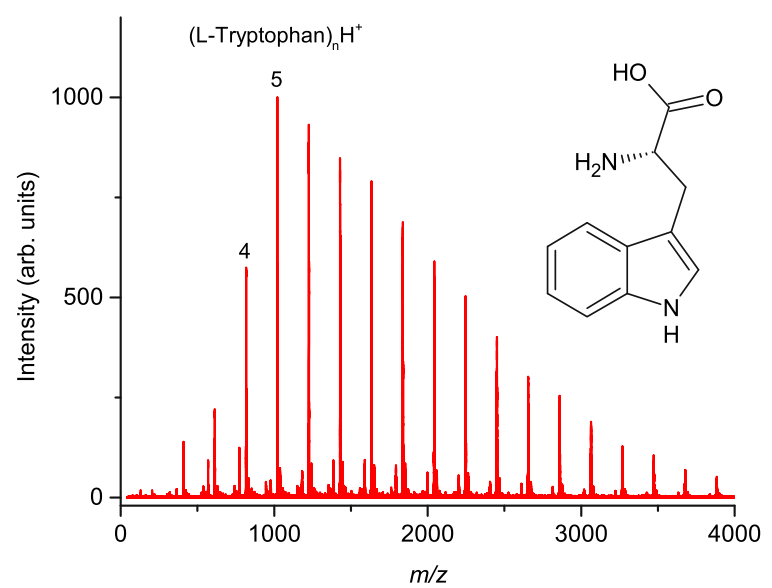

Fig. 3. Mass spectrum of positively charged ions formed upon pickup of L-tryptophan into charged He droplets. The dominant ions can be assigned to protonated tryptophan clusters $\left(\mathrm{C}_{1} 1 \mathrm{H}_{1} 2 \mathrm{~N}_{2} \mathrm{O}_{2}\right)_{n} \mathrm{H}^{+}$. The numbers above selected peaks designate the cluster size $n$ of the corresponding ion.

energy, some He atoms may remain attached to the amino acid clusters which is an indication of cold molecular cluster ions [26]. The resulting cluster size distribution under these gentle evaporation conditions is free of intensity anomalies or magic numbers, even for sodium cluster ions that exhibit prominent intensity anomalies due to electronic shell closures and spin pairing [32,33]. Pressures in the evaporation cell during the present experiments were typically $\sim 4.2 \times 10^{-4}$ mbar, which removed all He and additional vibrational excitation of cluster ions was leading to some monomer evaporation as indicated by the presence of intensity anomalies (magic numbers) in the spectrum of serine.

In addition, we used the MS/MS mode of the instrument enabling CID studies. There, single $m / z$ ions (precursor ions, p.i.) were selected by a quadrupole mass filter, accelerated and passed through a collision cell filled with Ar collision gas. During the present experiment the gas pressure in the $9 \mathrm{~cm}$ long collision cell was $\sim 1 \times 10^{-5}$ mbar.

At these settings, we were able to reach reasonable CID fragment ion signals up to $50 \mathrm{~V}$ of acceleration voltage. The fragment ions formed in the CID process were again transported to the TOF part of the instrument for $\mathrm{m} / \mathrm{z}$ analysis.

\section{Results}

In the present work, we prepare amino acid cluster ions in charged He droplets. We focus on low energy CID of these clusters, enabling us to explore the interplay of van der Waals and covalent bond fragmentation. We particularly focus on the differences between the stochiometric parent cations $\mathrm{M}_{n}^{+}$and the protonated clusters $\mathrm{M}_{n} \mathrm{H}^{+}$. Additionally we explore the 18 Da neutral loss fragmentation channel with respect to cluster ion polymerization.

The section is organized as follows: first, we present initial amino acid cluster distributions obtained after

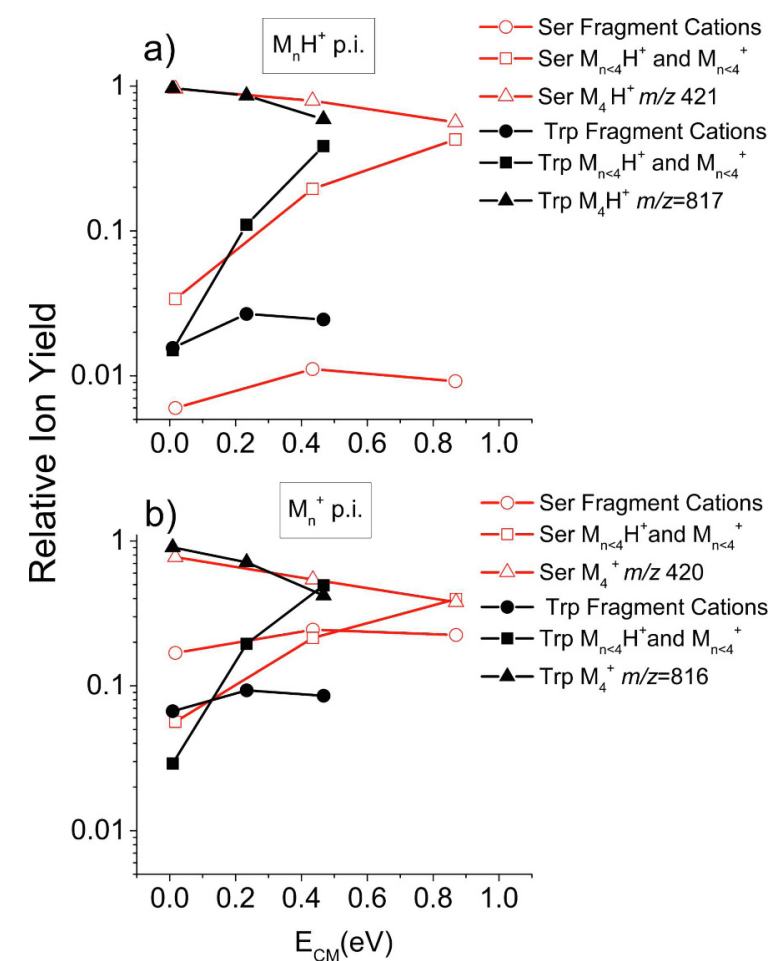

Fig. 4. Ion yield as a function of CID energy in the center of mass frame for (a) $\mathrm{M}_{4} \mathrm{H}^{+}$and (b) $\mathrm{M}_{4}^{+}$precursor ions. Depicted is always the precursor ion yield $\mathrm{M}_{4} \mathrm{H}^{+}$or $\mathrm{M}_{4}^{+}$, the yield of ions formed by evaporation of monomer units $\mathrm{M}_{n<4}^{+}$plus $\mathrm{M}_{n<4} \mathrm{H}^{+}$ and the yield of ions formed by fragmentation of monomer units - fragment cations.

evaporating the He droplets. Then we discuss different modes of decomposition for tetramer clusters. Finally, we focus on molecular fragmentation at higher center of mass (c.m.) collisional energies, enough to induce molecular fragmentation of the clusters.

Initial cluster distributions are shown in Figures 2 and 3. We can see that Ser tends to form more stable magic structures. Particularly, the magic octamer is well visible. In contrast, the spectrum of Trp is quite smooth. Fragmentation of the clusters is low, presumably due to the He droplet environment. The only channel that can be well recognized is the loss of the $\mathrm{COOH}$ group in the Trp spectrum. In order to liberate Ser cluster ions from the surrounding He droplets, harsher evaporation conditions were required, which in addition vibrationally activated the amino acid cluster ions and induced monomer evaporation. Particularly stable cluster ions, such as the octamer [34] are enhanced compared to their less strongly bound neighboring cluster sizes. Thus, the initial temperature of the Trp clusters may be lower, as will be discussed later.

\subsection{Cluster decomposition versus molecular fragmentation}

In the next step of the experiment, we introduced collisional Ar gas and focus on cluster decomposition. In Figure 4, we compare the evaporation and molecular 


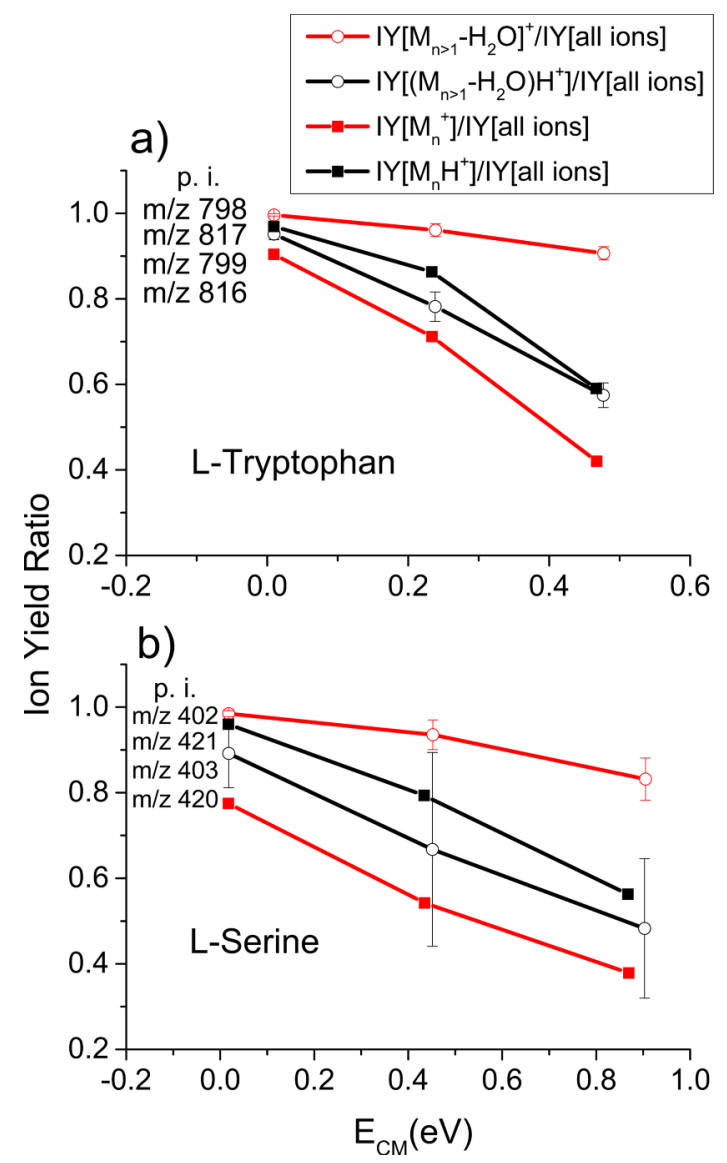

Fig. 5. Cluster ion stability, with respect to fragmentation and evaporation, demonstrated by plotting the ratio of p.i. ion yield to the total CID ion yield detected for a particular p.i. as a function of the collision energy. Panel (a) shows Trp ions, panel (b) shows Ser ions.

fragmentation of $\mathrm{M}_{4}^{+}$cluster cations and $\mathrm{M}_{4} \mathrm{H}^{+}$cluster cations by comparing ion yields of the ions formed after evaporation of monomer units with fragment ions, which are formed by the dissociation of monomer units.

At $0 \mathrm{eV}$ collisional energy, the decomposition of Ser clusters by evaporation of monomer units is more efficient than that of Trp. This can be attributed to higher initial internal energies of the clusters [35] gained during $\mathrm{He}$ evaporation in the case of Ser.

The energy dependence of the decomposition is much steeper for Trp. With increasing collision energy, the initial internal energy becomes less important and we can observe that Trp clusters decompose with higher efficiency. This is consistent with the structure of the molecules, where two $\mathrm{OH}$ groups of Ser provide more hydrogen bonding motifs.

At the studied energies, evaporation of monomer units is more probable than molecular fragmentation via covalent bond breakage. For $\mathrm{M}_{4}^{+}$the intensities of fragments due to evaporation of one or more monomers are $8 \%$ and $20 \%$ for Trp and Ser, respectively. For $\mathrm{M}_{4} \mathrm{H}^{+}$the molecular fragmentation yields are even lower, $2 \%$ for Trp and $0.7 \%$ for Ser. Taken together, $\mathrm{Ser}_{4}^{+}$is fragmenting more than
$\operatorname{Trp}_{4}^{+}$, while the order reverses in the case of protonated cluster cations.

\subsection{Water loss channel}

The "water loss" channel was proposed to be the doorway for peptide bond formation in small amino acid clusters. However, it is worth mentioning that the $m / z$ of ions forming after $18 \mathrm{Da}$ loss from protonated clusters is the same as the $m / z$ of ions forming after $17 \mathrm{Da}$ loss from nonprotnated clusters and the initial formation step of these ions cannot be unambiguously identified.

Figure 5 displays the CID energy dependence of fragmentation of the cluster cations. We can compare decomposition (fragmentation+evaporation) for $\mathrm{M}_{4}^{+}$and $\mathrm{M}_{4} \mathrm{H}^{+}$ with the ions formed after neutral loss of $18 \mathrm{Da}$. The slope of the $\mathrm{M}_{4}^{+}$and $\mathrm{M}_{4} \mathrm{H}^{+}$ions represents the slope of van der Waals cluster evaporation as we demonstrated in Figure 4. We can see that $\left(\mathrm{M}_{4}-\mathrm{OH}\right)^{+}$decomposes the same way while $\left(\mathrm{M}_{4}-\mathrm{H}_{2} \mathrm{O}\right)^{+}$requires more energy to fragment, which may indicate the presence of a covalently bound complex. While this is consistent with previous studies proposing cluster ion polymerization in amino acid clusters, it is worth mentioning two facts: first, in our case of reactions inside He droplets, the $\left(\mathrm{M}_{n}-\mathrm{H}_{2} \mathrm{O}\right)^{+}$fragmentation channel has very low intensity. Second, most of the studies of amide bond formation inside amino acid cluster ion cations were performed for protonated structures, which are the van der Waals bound $\left(\mathrm{M}_{4}-\mathrm{OH}\right)^{+}$according to our results.

\subsection{CID of amino acid clusters}

To further explore the character of bonding and relevance for peptide formation, we explore CID fragmentation at higher collision energies. The low signal levels of the small clusters do not allow to measure CID at acceleration voltages above $50 \mathrm{~V}$, corresponding to a c.m. energy for the Ser and Trp tetramer of $4.3 \mathrm{eV}$ and $2.3 \mathrm{eV}$, respectively. The respective fragmentation patterns are shown in Figure 6. At this energy the Ser tetramer still fragments primarily by the loss of monomer units and therefore we additionally measured CID fragmentation pattern for the Ser trimer at c.m. energy of $5.6 \mathrm{eV}$, which is shown in Figure 7 .

The section is divided according to the p.i.:

(i) $\mathrm{Ser}_{4,3}^{+} / \mathrm{Ser}_{4,3} \mathrm{H}^{+}$

as already mentioned, the Ser fragmentation pattern can be better resolved in Figure 7. The fragmentation pattern of protonated ions $\mathrm{M}_{n} \mathrm{H}^{+}$correlates with previous MS and MS/MS measurements of the molecule [23,24] as well as Ser containing peptides [36-38]. Three main fragments can be observed below the monomer mass, which are $\mathrm{m} / \mathrm{z}=88,70$ and 60 with respective assignments $(\mathrm{Ser}-\mathrm{OH})^{+},\left(\mathrm{Ser}-\mathrm{OH}-\mathrm{H}_{2} \mathrm{O}\right)^{+}$and $(\mathrm{Ser}-\mathrm{COOH})^{+}$. The fragmentation patterns of protonated and nonprotonated clusters below the $\mathrm{m} / z$ of the monomer are practically identical. The spectrum above the $\mathrm{m} / \mathrm{z}$ of the 


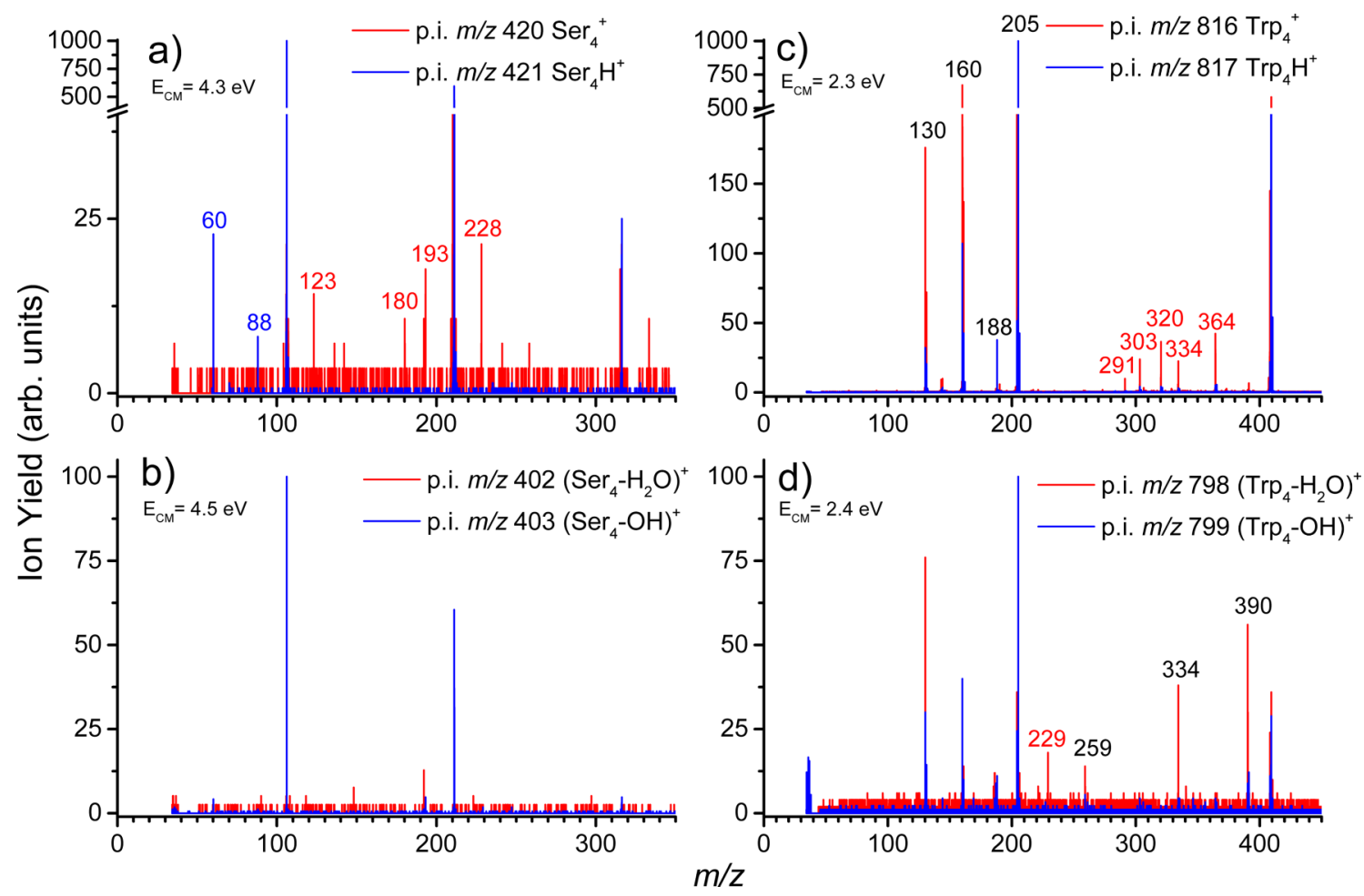

Fig. 6. CID fragmentation patterns of $\mathrm{M}_{4}^{+}$and $\mathrm{M}_{4} \mathrm{H}^{+}$cluster ions of Ser (a) and Trp (c). CID fragmentation patterns of their dehydrated analogs $\left(\mathrm{M}_{4}-\mathrm{H}_{2} \mathrm{O}\right)^{+}$and $\left(\mathrm{M}_{4}-\mathrm{OH}\right)^{+}$for Ser $(\mathrm{b})$ and $\operatorname{Trp}(\mathrm{d})$.

monomer shows significant differences. While $\mathrm{M}_{n} \mathrm{H}^{+}$fragments mainly by the evaporation of monomer units, $\mathrm{M}_{n}^{+}$ exhibit significant fragmentation of the monomer units. The most pronounced ions are $m / z=193,180$ and 123 . The $m / z=193$ cation may be assigned to the protonated dipeptide. The later two ions $m / z=180$ and 123 , however, cannot be assigned to peptide fragments but are rather fragment cluster cations ( $\mathrm{Ser}_{2}$-formaldehyde) ${ }^{+}$and $\left(\mathrm{Ser}+\mathrm{H}_{2} \mathrm{O}\right)^{+}$.

(ii) $\left(\mathrm{Ser}_{4,3}-\mathrm{H}_{2} \mathrm{O} / \mathrm{OH}\right)^{+}$

again below the $m / z$ of the monomer, fragmentation patterns of $\left(\mathrm{M}_{n}-\mathrm{OH}\right)^{+}$and $\left(\mathrm{M}_{n}-\mathrm{H}_{2} \mathrm{O}\right)^{+}$ions are similar to that of $\mathrm{M}_{n}^{+}$and $\mathrm{M}_{n} \mathrm{H}^{+}$ions. However, we can see that more energy is required to fragment these ions. Above the $m / z$ of the monomer, $\left(\mathrm{M}_{n}-\mathrm{OH}\right)^{+}$fragments to $m / z=124$ and 142 , corresponding to $\left(\mathrm{Ser}+\mathrm{H}_{2} \mathrm{O}\right) \mathrm{H}^{+}$and $\left(\mathrm{Ser}+\left(\mathrm{H}_{2} \mathrm{O}\right)_{2}\right) \mathrm{H}^{+} .\left(\mathrm{M}_{n}-\mathrm{H}_{2} \mathrm{O}\right)^{+}$fragments to $m / z=192$ corresponding to the dipeptide cation forming by evaporation of two molecules from the tetramer (Fig. 6) or one molecule from the trimer (Fig. 7), and $m / z=118$ which again cannot be assigned to a peptide fragment but has rather the form of a fragment cluster cation $(\mathrm{Ser}+\mathrm{CH})^{+}$.

The strong signal of the $m / z=192$ fragment after the dissociation of the $\left(\mathrm{M}_{n}-\mathrm{H}_{2} \mathrm{O}\right)^{+}$is in contrast to the fragmentation of the $\left(\mathrm{M}_{n}-\mathrm{OH}\right)^{+}$cation, illustrating again that the cations formed after neutral loss of $18 \mathrm{Da}$ are more strongly bound in the case where the additional proton is not available.

(iii) $\operatorname{Trp}_{4}^{+} / \operatorname{Trp}_{4} \mathrm{H}^{+}$

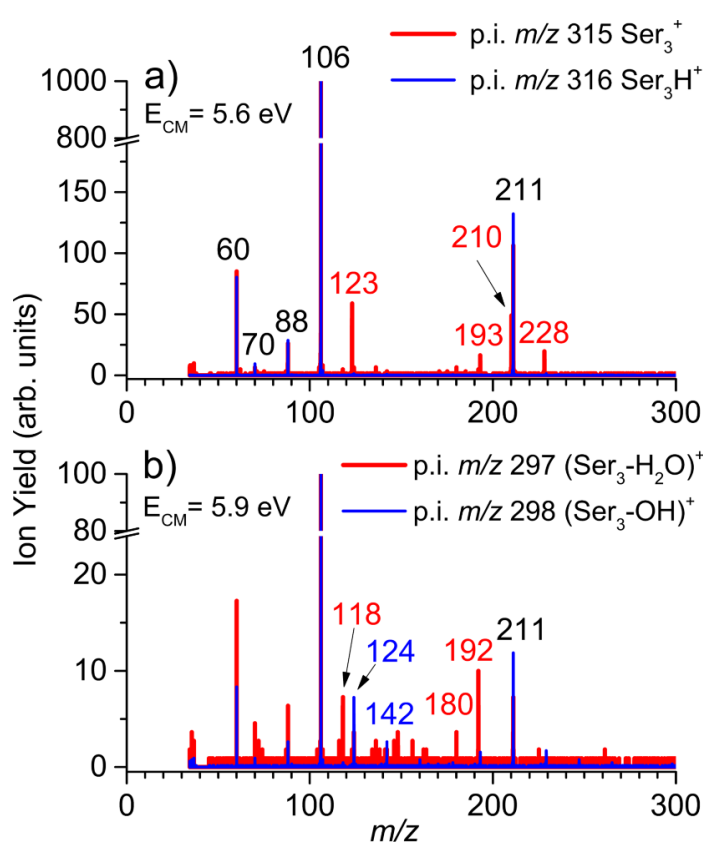

Fig. 7. CID fragmentation patterns of $\mathrm{Ser}_{3}^{+}$and $\mathrm{Ser}_{3} \mathrm{H}^{+}$cluster cations (a) and their dehydrated analogs $\left(\mathrm{Ser}_{3}-\mathrm{H}_{2} \mathrm{O}\right)^{+}$and $\left(\mathrm{Ser}_{3}-\mathrm{OH}\right)^{+}$.

Trp $\mathrm{M}_{n} \mathrm{H}^{+}$fragments to $m / z=188,160$ and 130 ions. In contrast to Ser, the $\left(\mathrm{M}+\left(\mathrm{H}_{2} \mathrm{O}\right)_{n}\right)^{+}$ions are not observed. The ion with $m / z=130$, corresponding to the side chain cation, is the most intense fragment after 
electron ionization [39] or photoionization $[40,41]$ of isolated gas phase Trp. The ion with $m / z=188$, formed after $\mathrm{NH}_{3}$ loss from the protonated $\mathrm{TrpH}^{+}$, is very stable and was observed as the only product of $\mathrm{TrpH}^{+}$metastable ion decay [42] after fast atom bombardment of amino acid solutions. After collisional activation of $\mathrm{TrpH}^{+}$, the $m / z=130$ ion was observed $[42,43]$, which is again in agreement with the present spectra. In previous works on CID of amino acids and peptides also $\mathrm{m} / z=159$ cations, corresponding to the important immonium cation were reported, however, with low intensities $\sim 2 \%$. In the present spectra, we detect $m / z=160$ cations instead and with high intensities, corresponding to neutral loss of the carboxyl group. $\mathrm{M}_{n}^{+}$dissociates into the same fragments below the $m / z$ of the monomer, but with higher intensity. This is the opposite to the behavior observed for Ser, where the $\mathrm{M}_{n}^{+}$ions fragment less. Above the mass of the monomer there is a new region of fragment cluster ions with $m / z=291,303,320,334,364$. These ions corresponding to masses $m / z=364\left(\operatorname{Trp}_{2}-\mathrm{CO}_{2}\right)^{+}, m / z=$ $334(\operatorname{Trp}+\mathrm{R})^{+}, m / z=320(\operatorname{Trp}+\mathrm{R}-\mathrm{CH})^{+}, m / z=291$ $\left(\operatorname{Trp}_{2}-\mathrm{R}+\mathrm{C}\right)^{+}$, where $\mathrm{R}=\mathrm{C}_{9} \mathrm{NH}_{8}$, can be assigned directly to cationic complexes of Trp with ionic fragments of a second molecular unit of the cluster. For $\mathrm{m} / z=303$ (tentatively $\left(\operatorname{Trp}+\mathrm{C}_{4} \mathrm{H}_{5} \mathrm{NO}_{2}\right)^{+}$) such assignment is not straightforward since it requires an opening of the ring or participation of a third molecular unit of the cluster.

(iv) $\left(\operatorname{Trp}_{4,3}-\mathrm{H}_{2} \mathrm{O} / \mathrm{OH}\right)^{+}$

fragmentation of the $\left(\mathrm{M}_{n}-\mathrm{OH}\right)^{+}$precursor ions is the same as for the $\mathrm{M}_{n} \mathrm{H}^{+}$ions. For $\left(\mathrm{M}_{n}-\mathrm{H}_{2} \mathrm{O}\right)^{+}$, fragments are the same below the $\mathrm{m} / \mathrm{z}$ of the monomer. Above the mass of the monomer, fragmentation of the $\mathrm{M}_{n}^{+}$and $\left(\mathrm{M}_{n}-\mathrm{H}_{2} \mathrm{O}\right)^{+}$ions is significantly different. New cluster fragment ions are $m / z=229, m / z=259$ and $m / z=390$. Mass $390 \mathrm{Da}$ corresponds to the dipeptide and similar to Ser case, the intensity of the signal of this cation is much stronger after CID of $\left(\operatorname{Trp}_{4}-\mathrm{H}_{2} \mathrm{O}\right)^{+}$than of the $\left(\operatorname{Trp}_{4}-\mathrm{OH}\right)^{+}$. The ion with $m / z=334$ is $(\operatorname{Trp}+\mathrm{R})^{+}$, which can be again directly assigned to complexes of Trp with ionic fragments of a second molecular unit of the cluster. The ion $m / z=229$ stoichiometrically corresponds to $\left(\operatorname{Trp}+\mathrm{C}_{2} \mathrm{H}\right)^{+}$, however, may have a different structure. The ion with $m / z=259$ cannot be assigned in the present experiment.

Generally, we can see that only ions that can be directly assigned to the formation of dipeptides in the clusters are parent dipeptide ions that are formed with much higher intensities from $\mathrm{M}_{n}^{+}$in comparison to $\mathrm{M}_{n} \mathrm{H}^{+}$precursors. Fragment ions below the $m / z$ of the monomer can be assigned to the fragmentation of peptides, but it is caused only by the fact that known peptide residue ions are mostly identical to monomer or protonated monomer dissociation products. The fragments observed at masses above the $m / z$ of the monomer can be assigned to cluster ion complexes of molecules and fragments and practically none of them will be easily attributable to the dissociation of dipeptide ions $[44,45]$. The question therefore remains, if the detected ions corresponding to the dipeptide $\mathrm{m} / \mathrm{z}$ do really have dipeptide structure, which unfortunately cannot be answered in the present experiments.

\section{Conclusions}

We prepared Ser and Trp cluster cations inside He droplets using a novel cluster ion assembly technique. We show that the cluster ions prepared this way can be thermalized with the He matrix or vibrationally activated, depending on the conditions set in the RF-hexapole which liberates the dopant cluster ions from the host helium droplets.

Using CID at low c.m. energies, we demonstrated that noncovalent bonding, as well as molecular stability against dissociation, is higher for $\mathrm{Ser}_{n}^{+}$clusters.

The CID energy dependencies show that except for the $\left(\mathrm{M}_{n}-\mathrm{H}_{2} \mathrm{O}\right)^{+}$p.i. all the studied p.i. types $\mathrm{M}_{n}^{+}, \mathrm{M}_{n} \mathrm{H}^{+}$ and $\left(\mathrm{M}_{n}-\mathrm{OH}\right)^{+}$are only weakly, presumably van der Waals, bound. This observation is confirmed also by CID mass spectra at $50 \mathrm{eV}$ lab frame CID energy inducing molecular fragmentation. At this energy, $\mathrm{M}_{n}^{+}, \mathrm{M}_{n} \mathrm{H}^{+}$and $\left(\mathrm{M}_{n} \mathrm{H}-\mathrm{H}_{2} \mathrm{O}\right)^{+}$fragment nearly exclusively by evaporation of monomer units, while a significant amount of $\left(\mathrm{M}_{n}-\mathrm{H}_{2} \mathrm{O}\right)^{+}$p.i. dissociate to fragment ions with $m / z$ values typical of dipeptides.

However, except for the ions detected at the $m / z$ of dipeptides, there is no other evidence of peptide formation in the fragmentation spectra. Therefore, other structures of the same $m / z$ cannot be excluded in the present experiment. Optical spectroscopy techniques could give a clear answer on the formation of peptide bonds.

Open access funding provided by University of Innsbruck and Medical University of Innsbruck. This work was supported by EFRE (K-Regio project FAENOMENAL, grant number EFRE 2016-4) and the Austrian Science Fund FWF (project number P31149). J.K. acknowledges the support from Czech Ministry of Education Youth and Sports via OP RDE. Grant no. CZ.02.2.69/0.0/16_027/0008355. We thank Thomas F.M. Luxford for proofreading the revised manuscript.

\section{Author contribution statement}

L.T. and J.K. performed the experiments and analyzed the data. J.K. prepared draft of the manuscript that has been improved by P.S. All authors read and corrected the final and revised versions of the manuscript.

Open Access This is an open access article distributed under the terms of the Creative Commons Attribution License (https://creativecommons.org/licenses/by/4.0/), which permits unrestricted use, distribution, and reproduction in any medium, provided the original work is properly cited.

Publisher's Note The EPJ Publishers remain neutral with regard to jurisdictional claims in published maps and institutional affiliations.

\section{References}

1. A.E. Counterman, D.E. Clemmer, J. Phys. Chem. B 105, 8092 (2001)

2. R.G. Cooks, D. Zhang, K.J. Koch, F.C. Gozzo, M.N. Eberlin, Anal. Chem. 73, 3646 (2001) 
3. R. Hodyss, R.R. Julian, J.L. Beauchamp, Chirality 13, 703 (2001)

4. X. Kong, I.A. Tsai, S. Sabu, C.C. Han, Y.T. Lee, H.C. Chang, S.Y. Tu, A.H. Kung, C.C. Wu, Angew. Chem. Int. Ed. 45, 4130 (2006)

5. F. Ferreira da Silva, P. Bartl, S. Denifl, T.D. Märk, A.M. Ellis, P. Scheier, ChemPhysChem 11, 90 (2010)

6. M. Nihamkin, A. Kaiser, I. Nemtsov, P. Martini, P. Scheier, Y. Mastai, Y. Toker, Int. J. Mass Spectrom. 446, 116215 (2019)

7. Z. Takats, S.C. Nanita, R.G. Cooks, Angew. Chem. Int. Ed. 42, 3521 (2003)

8. S. Gronert, R.A.J. O'Hair, A.E. Fagin, Chem. Commun. 17, 1944 (2004)

9. K.J. Koch, F.C. Gozzo, S.C. Nanita, Z. Takats, M.N. Eberlin, R.G. Cooks, Angew. Chem. Int. Ed. 41, 1721 (2002)

10. I. Weissbuch, M. Lahav, Chem. Rev. 111, 3236 (2011)

11. K. Ruiz-Mirazo, C. Briones, A. de la Escosura, Chem. Rev. 114, 285 (2014)

12. M. Speranza, Int. J. Mass Spectrom. 232, 277 (2004)

13. M. Klussmann, H. Iwamura, S.P. Mathew, D.H. Wells, U. Pandya, A. Armstrong, D.G. Blackmond, Nature 441, 621 (2006)

14. H. Wincel, R.H. Fokkens, N.M.M. Nibbering, Rapid Commun. Mass Spectrom. 14, 135 (2000)

15. S. Lee, S.J. Valentine, J.P. Reilly, D.E. Clemmer, J. Am. Chem. Soc. 133, 15834 (2011)

16. S. Lee, R.R. Julian, S.J. Valentine, J.P. Reilly, D.E. Clemmer, Int. J. Mass Spectrom. 316-318, 6 (2012)

17. W.M. McGee, S.A. McLuckey, Proc. Natl. Acad. Sci. 111, $1288(2014)$

18. E.C. Griffith, V. Vaida, Proc. Natl. Acad. Sci. 109, 15697 (2012)

19. M. Pech, K.H. Nierhaus, ChemBioChem 13, 189 (2012)

20. P.A. Leclercq, D.M. Desiderio, Org. Mass Spectrom. 7, 515 (1973)

21. C.W. Tsang, A.G. Harrison, J. Am. Chem. Soc. 98, 1301 (1976)

22. A. Singh, S. Kaur, J. Kaur, P. Singh, Rapid Commun. Mass Spectrom. 28, 2019 (2014)

23. G. Junk, H. Svec, J. Am. Chem. Soc. 85, 839 (1963)

24. G.E. Reid, R.J. Simpson, R.A. OHair, J. Am. Soc. Mass Spectrom. 11, 1047 (2000)

25. R. Frański, Amino Acids 51, 1241 (2019)

26. L. Tiefenthaler, J. Ameixa, P. Martini, S. Albertini, L. Balluf, M. Zankl, M. Goulart, F. Laimer, F. Zappa, P. Scheier, RSI 91, 033315 (2020)
27. A. Kramida, Y. Ralchenko, J. Reader, NIST ASD Team, NIST Atomic Spectra Database (ver. 5.7.1) [Online], https://physics.nist.gov/asd [2019, November 5] (National Institute of Standards and Technology, Gaithersburg, MD, 2019)

28. D.M. Close, J. Phys. Chem. A 115, 2900 (2011)

29. F. Gaie-Levrel, G.A. Garcia, M. Schwell, L. Nahon, Phys. Chem. Chem. Phys. 13, 7024 (2011)

30. A. Mauracher, O. Echt, A. Ellis, S. Yang, D. Bohme, J. Postler, A. Kaiser, S. Denifl, P. Scheier, Phys. Rep. 751, 1 (2018)

31. M.R. Lalanne, G. Achazi, S. Reichwald, A. Lindinger, Eur. Phys. J. D 69, 280 (2015)

32. W.D. Knight, K. Clemenger, W.A. de Heer, W.A. Saunders, M.Y. Chou, M.L. Cohen, Phys. Rev. Lett. 52, 2141 (1984)

33. W.A. de Heer, Rev. Mod. Phys. 65, 611 (1993)

34. V. Scutelnic, M.A.S. Perez, M. Marianski, S. Warnke, A. Gregor, U. Rothlisberger, M.T. Bowers, C. Baldauf, G. von Helden, T.R. Rizzo, J. Seo, J. Am. Chem. Soc. 140, 7554 (2018)

35. D.A. Hales, P.B. Armentrout, J. Cluster Sci. 1, 127 (1990)

36. H.J. Svec, G.A. Junk, J. Am. Chem. Soc. 86, 2278 (1964)

37. W. Heerma, W. Kulik, Biomed. Environ. Mass Spectrom. 16, 155 (1988)

38. Y. Liang, P. Neta, X. Yang, S.E. Stein, J. Am. Soc. Mass Spectrom. 29, 463 (2018)

39. S.E. Stein, director, in NIST Mass Spec Data Center "Mass Spectra" in NIST Chemistry WebBook, NIST Standard Reference Database Number 69, edited by P.J. Linstrom, W.G. Mallard (National Institute of standards and Technology, Gaithersburg MD 20899, June 2014), p. 127959, http://webbook.nist.gov

40. K.R. Wilson, M. Jimenez-Cruz, C. Nicolas, L. Belau, S.R. Leone, M. Ahmed, J. Phys. Chem. A 110, 2106 (2006)

41. T.R. Rizzo, Y.D. Park, D.H. Levy, J. Am. Chem. Soc. 107, 277 (1985)

42. W. Kulik, W. Heerma, Biomed. Environ. Mass Spectrom. 15, 419 (1988)

43. P. Zhang, W. Chan, I.L. Ang, R. Wei, M.M.T. Lam, K.M.K. Lei, T.C.W. Poon, Sci. Rep. 9, 6453 (2019)

44. I.A. Papayannopoulos, Mass Spectrom. Rev. 14, 49 (1995)

45. B. Paizs, S. Suhai, Mass Spectrom. Rev. 24, 508 (2005) 